\title{
NATURALISM AND THE INVENTION OF IDENTITY
}

Marilyn Strathern

\begin{abstract}
Its author ever hopeful of abandoning nature-culture or nature-society, this brief sketch is an attempt to understand some part of the dyad. It fishes among materials on biological relatedness, ideas about reproduction, and configurations of kinship that might amount to a naturalist cosmology, detectable among other things in the problems it generates. There is nothing new in apprehending how much of society was already 'in' the nature that came to be distinguished from it. However, the anthropologist's net has its own gauge, and thus the argument at once depends on historical niceties and disregards them. What gets caught in the mesh flung over this huge area are certain issues concerning identity and individuality. These demand a closer inquiry into the character of the relations being supposed, the matter with which the article opens.
\end{abstract}

Keywords: European kinship, kin terms, moderns, naturalism, personal identity, relations

Our bodies must be understood as holobionts, whose anatomical, physiological, immunological, and developmental functions evolved in shared relationships of different species. (Gilbert et al. 2012: 334)

Not so long ago, an article on symbiosis appeared in the Quarterly Review of Biology (Gilbert et al. 2012) outlining the essential interactions between species entailed in the contribution of microbes to forming and sustaining life. ${ }^{1}$ Given that its authors are historians and philosophers of biology, perhaps it is not surprising that they began with reference to the early modern period in Europe and a discussion of concepts of individuality. They argued (after Charles Taylor) that the general notion of the autonomous individual agent, as understood then, framed the study of life forms later known as biology. Today, they wrote 
of organisms, "all classical conceptions of individuality are called into question by evidence of all-pervading symbiosis" (ibid.: 327).

In their tracing of non-individual-based notions, from organic systems or ecologies to the vocabulary of symbionts and holobionts, Gilbert et al. (2012) drew both on behavioral concepts, such as interaction or communication, and on a broader, more abstract conceptualization of 'relations', 'relationships'. That is where I would lay my own question. If Euro-Americans are to continue trying to shake off-it seems a never-ending task-restrictive notions of individuality, I wonder if they do not need alternative ways of thinking about relations as well. This is not least because in much conventional parlance relations presuppose already existing entities. So when our authors talk of "inter-active relationships among species" (ibid.: 326), the terms of the relation become, epistemically speaking, individualized. Of course, the problem has been taken up in numerous locations outside biology. ${ }^{2}$ Yet perhaps we have not said everything that we need to say about relations. The concept may turn out to be at once key for comprehending symbiosis and a linguistic impediment to describing it.

This article considers some issues in the way that relations, epistemic and otherwise, have been imagined by Euro-Americans and what these selfacknowledged moderns (after Latour 2013b) may have been hiding from themselves. If it requires venturing into the kinds of subject matter that concern historians and philosophers, without being able to take advantage of their perspectives, it will become apparent that what is offered here is not meant to compete with them. An interest in evolving notions of biology, and of nature at large, it is argued, might spare a glance at people's ways of thinking about reproduction and at changing configurations of kinship.

\section{Internal and External Relations}

From work in Amazonia that has now become a locus classicus of debates about European cosmology, Viveiros de Castro (2004: 472) lays out one of its fundamentals, a contrast between relational and non-relational substantives: "Kinship terms are relational pointers; they belong to the class of nouns that define something in terms of its relations to something else ... Concepts like fish or tree, on the other hand, are proper, self-contained substantives: they are applied to an object by virtue of its intrinsic properties." Self-contained substantives appear in stark contrast to those of Amerindian perspectivism, where entities "named by substantives like fish, snake, hammock, or beer are somehow used [emphasis added] as if they were relational pointers, something halfway between a noun and a pronoun ... [Speaking generally,] [y]ou are a father only because there is another person whose father you are. Fatherhood is a relation, while fishiness is a[n] intrinsic property of fish. In Amerindian perspectivism, however, something is a fish only by virtue of someone else whose fish it is" (ibid.: 472-473).

Viveiros de Castro (2004: 473) invites us to imagine that all Amerindian substances are of this sort: "Suppose that, as siblings are those who have the same 
parents, conspecifics are those that have the same fish, the same snake, the same hammock, and so forth. No wonder, then, that animals are so often conceived, in Amazonia, as affinely related to humans. Blood is to humans as manioc beer is to jaguars in exactly the way that my sister is the wife of my brother-in-law." There might be an analogical inflection to Euro-American sibling and in-law relations, but not to the way they think of blood or beer. And here Viveiros de Castro's argument prompts a further thought. For Euro-American moderns, the relativity of kinship does not seem all-pervasive. While kin terminology remains an exemplar of relative thinking, since the terms imply relations, when the terms are thought of with respect to their referents-kinspersons-they are often used as if they too were "proper, self-contained substantives." That is, indeed, just how they might think of blood or beer. In the way they treat one another, kinsfolk are not regularly sustained as relatives through, for example, analogies with other relatives. Rather, as Schneider pointed out long ago for American kinship, they have first to be sustained as (individual) persons, as a mother, uncle, cousin, each with his or her own intrinsic mode of behavior or quality of relating.

We can gloss the Euro-American position by generalizing a contrast made by both Morita (2014) and Jensen (2012), namely, between internal and external relations. ${ }^{3}$ Kin terms point to internal relations (a relation is implied in the term), while it is external relations that link kinspersons as more or less selfcontained beings. The distinction is found in modern philosophy where it has its own complex trajectory, but from which I retain a simple difference between the relativity of internal relations (relations and relata being mutually defining) and the contingency of external relations. External relations are contingent on the character or quality of what is being related. In this Euro-American cosmology, classificatory schemes commonly define entities in relation to one another according to their intrinsic properties that enable the classifier to commensurate-bring into a single relation ${ }^{4}$ - the sameness/difference of each with respect to the other. The (external) relation between them keeps the separateness of the terms in play. Tautology is evident: externality resides in the prior distinctiveness of the 'different' entities being related-in short, in perceptions of the fishiness of fish or of the fatherly qualities of the father.

Attributing such thinking to a distinct cosmology is stimulated by Descola's (2013) Beyond Nature and Culture. What he calls 'naturalism' is one of four experiential regimes ${ }^{5}$ by which people identify and make relations with what is around them, 'identification' and 'relating' being, in his thesis, basic modalities in the structuring of individual and collective experiences. A preliminary distinction between internal and external relations is crucial: "Relationships are thus here understood not in a logical or mathematical sense (i.e., as intellectual operations that make it possible to establish an internal link between two concepts) but rather as the external links between beings and things that are detectable in typical behavior patterns and may be partially translatable into concrete social norms" (ibid.: 113). While identification involves a relation insofar as "it is based on judgments of inherence and attribution" of specific properties (ibid.), that relation remains intrinsic to the object identified, and 
when Descola talks of relations, his concern is with "the connections that this object has with something other than itself" (ibid.: 114).

Now whether or not such conceptions of 'identification' and 'relating' make sense as part of the naturalist cosmology, within which anthropology has itself flourished, it seems that there have been times when kinship and its reproductive potential have sat rather uneasily athwart them. In fact, the anthropologist might want to know why kin relations in some regimes are the very exemplars of cosmology, while in this one they are repeatedly pushed to one side.

\section{A High Point in the Naturalist Tradition}

The European concept of biology took popular hold in nineteenth-century England. Experiments in plant and animal husbandry had led to a scientific literature on the effects of selective breeding, and "debates about the value of creating healthy stock by introducing new hybrid strains, or the oppositeincreasing quality and quantity by 'breeding in and in'-became more widely known" (Davidoff 2012: 239). That similar effects could be observed in human populations came to color concerns about heredity and the substance of connections between kin. If the capacious concept of nature expanded to embrace biology, it also emphasized reproduction as a physiological phenomenon.

For diverse reasons and variably according to social strata, in the same century marriage between close kin became widespread across Europe (Sabean 2007a, 2007b). ${ }^{6}$ High rates of cousin marriage reflected repeated unions between families, both within and across the generations, and the English bourgeois were no exception. An anthropological study (Kuper 2009) pinpoints what was often expressed as desirable intimacy, the closeness of natal family members being assimilated to the closeness of affinally related ones. It is of this period that literary scholars "noted that the legitimate desire for a cousin sometimes appears [in works of the time] as a stand-in for forbidden attraction to a brother or sister" (Davidoff 2012: 239). Forbidden though it might be, the extravagant sentiment that close family members could display for one another underlined a mutual resemblance with conjugal relations. In public, there was vigorous debate on whether the incest taboo was "a law of nature" or whether marriage restrictions were rather "the fruit of civilization" (Kuper 2009: 101). By contrast with other controversies, ${ }^{7}$ the protagonists "appealed to science, not theology" (ibid.: 83) and argued over the physiological effects of close unions as they showed in their offspring. Anthropologists came on the scene at this point, talking about primitive kinship and the evolution of society.

Suppose we approached this as though we were in a naturalist world where entities can be defined by intrinsic properties, the classification of substances-including reproductive material-being ordered through their external relations with one another. When Descola (2013: 239) says that naturalism privileges terms over relations, he means to point to what is generally taken for granted as a sense of the prior existence of things. That would not of course say anything about the precariousness of ordering and its relational 
effects (Law 1994: 23), only that outside philosophical and critical reflection, moderns are effective in hiding it (the precariousness). Arguably, it is just such precariousness that kinship arrangements sometimes revealed. A supposedly natural order of kinship might rest on a schema of external relations, yet could the latter's externalizing and differentiating effect be rendered ambiguous, to the point of ambiguity being an object of attention, by over-insistence on it? Take practices of familial closeness. ${ }^{8}$ Relationally speaking, there was nothing to supplement knowledge of the appropriate ('natural') ways of acting. Brother and sister, husband and wife: there are no internal relations here to hold kinspersons in place, through, for example, deliberate analogic referencing, only the appropriate behavior ascribed to (the nature of) each person. As suggested earlier, every kin designation may be internally relational (a 'brother' implying a brother or sister), but in being occupied by persons, the kinship positions do not control or govern each other as the terms to an internal relation do. ${ }^{9}$ Instead, it seems, kinspersons relied on discriminating between different registers of intimacy and closeness.

There were many problems attributed to kin relations at the time, but not this one. Only with hindsight do kinship and its reproductive potential appear to be a problem with respect to one of the major preoccupations of the Enlightenment that the bourgeois of nineteenth-century England inherited: nature as at once a positive and a negative force in human affairs. The problem of kinship was hidden, both through its often remarked relegation to domestic affairs and through the eclipse of older understandings by the very concept of nature as such. Now biologized, as it came to be in concerns voiced over reproduction in marriage, nature was reinvented in the significance it carried for the behavior of kinspersons toward one another. Among other things, this stimulated the embryonic field called anthropology and what became its debates over 'nature-culture'.

\section{Inventions: Identity and Relations}

The debates did not of course begin then. But they might have taken a different shape if it had not been for certain early modern developments in ideas about relations, both epistemic and interpersonal. Vilaça (2013: 364) offers an arresting correlation between the birth of the notion of the individual and the identification of nature and culture as discrete domains. ${ }^{10}$ An obvious entailment of imagining that there is a relation between nature and culture, and that it is an external one, is to keep separate the terms (nature, culture) of what may otherwise be-and in the eyes of many should only be-imagined as an internal relation of mutual implication. This is where anthropologists have focused much remedial work. ${ }^{11}$ My own concern is with a tangential observation: when 'individuals' and the 'identity' of phenomena become prominent, as they did among other things in the attention given them by scholarly inquiry, so too do (external) 'relations' (colloquially put, as though there were at once more individuals and more relations around). For external relations at once hold things apart and hold them in place, that is, sustain their identities. If we were to seek 
examples, then what we know of certain early modern trends in relations of kinship is highly suggestive. On the one hand appeared new ${ }^{12}$ ways of talking about persons without talking about kin positions as such; on the other hand one's relatives, like one's family's connections, could be thought of as extensions or additions beyond and external to the self. Out of a vast field of possibilities, I touch on two moments: the invention of 'identity' and the changing character of reproductive substance.

It is to the scientific and philosophical innovations of the European seventeenth century that we owe the concept 'identity'. ${ }^{13}$ It became applied to the self-sameness of persons quite as much as of things, something of an irony in that for philosophers who drew examples from familiar experience one's self was the most unstable of entities. They argued over whether a person, understood as a self, could be a permanent subject, given all the variations in time, place, states of consciousness, and so forth, of which people were aware in themselves. The issue neither began nor ended with early modern writers, but they provided a new vocabulary for it. This put questions about persons into a wider field of inquiry concerning the identity of things.

Personal identity or the self, one well-known English philosopher, John Locke (1632-1704), ${ }^{14}$ declared in 1690, "is not determined by identity or diversity of substance, which it cannot be sure of, but only by identity of consciousness" or understanding (see Locke [1690] 1975: chap. 27:23, 345). The purpose in quoting Locke is to point to what was under debate, that is, "the riddle of identity" (Porter 2000: 166). It was a question of discerning the intrinsic qualities by which the self could be defined. Porter reports of others who found the same instability in consciousness that Locke did in substance (flesh, matter), arguing, for example, that perception was discontinuous and divisible. ${ }^{15}$ Taylor (1989: 171-172) - the political scientist and twentieth-century guide for the philosophers of biology concerned with individualityreflects on Locke's “unprecedentedly radical form of self-objectification ... [enabling us] to see ourselves as objects of far-reaching reformation ... To take this stance is to identify oneself with the power to objectify and remake, and by this act to distance oneself from all the particular features which are objects of potential change [such as substance] ... This power reposes in consciousness." In the 'person', then, the seventeenth-century philosopher is dealing with a thinking, intelligent being. When by contrast he comes to talk of the permanent sameness of 'man' (the individual living organism, or human being in later parlance), ${ }^{16}$ the identity of man is not differently conceived from that of plants or animals: "For in them the variation of great parcels of matter alters not the identity ... [A] plant which has ... an organization of parts in one coherent body, partaking of one common life, ... continues to be the same plant as long as it partakes of the same life" (Locke [1690] 1975: chap. 27:3-4, 330-331). ${ }^{17}$ Apropos the objectification to which Taylor refers, different questions are being asked of plants, animals, and man, on the one hand, and of the person, on the other. For although, Locke says, we "know that, in the ordinary way of speaking, the same person, and the same man, stand for one and the same thing" (ibid.: chap. 27:15, 251), thought on the issue reveals 
a radical divergence between the way in which the identity of persons and the identity of man are formed.

Dare we ask what kind of 'biology' this is? The discussion about personal identity and living organisms makes no mention of kinship, despite it being quite prominent elsewhere. Locke drew on kinship in order to provide concrete examples of an otherwise abstract conception, namely, relations, but not when it came to person as self or to man as human being. He neither depicted persons and selves as kinspersons nor pondered on the procreation and nurture of man as a reproductive being. ${ }^{18}$ Neither figure was categorically held in place by its kinship with others; instead, 'person' had quasi-theological/moral characteristics ('consciousness'), while 'man' had natural ones ('life', 'an organization of parts'). Given that kin ties were useful ways to illustrate relations, thus entwined the absence of one implied the absence of the other. Conversely, kinship could have been the link that brought relations to mind, or relations could have done so for kinship. As it was, the discussion about the identity of persons or the identity of human beings was held separate from a discussion about the formation of relations. ${ }^{19}$ And if understanding relations is not an intrinsic part of understanding either, are we to conclude that kinship too, being entwined with questions about relations as it is, finds itself extraneous to the dual concepts of person or man? Whether between persons or between men, that would make kin relations a matter of 'external' linkage. The reader is invited to imagine a being whose relations-including those of kinship-lie outside its essential nature.

Yet apropos the anachronistic speculation, asking what kind of 'biology' was being imagined for an inquiry into the characteristics of persons and human beings, perhaps the option of drawing on 'kinship' (what? whose?) was never open. For that would be to discount the influence of certain ideas about kinspersons, families, and interpersonal connections that were also traveling along the same route as, and enrolled the self-same concepts of, identities external to one another.

\section{Rehearsing the Familiar}

Standing back, an anthropologist might wish to take the very implication of rendering relations external both to the individual organic being and to the conscious person or self $a s$ an emergent modeling of kinship. The notion of an entity with (external) relations to others echoes some of the ways people of the time were apparently coming to think about kin ties, and this was not confined to England. Eighteenth-century Europe experienced new sentiments of alliance and new patterns of "interlocking networks of kindred" alongside "social and familial endogamy” (Sabean and Teuscher 2007: 16). But while, according to these historians of Europe (see Johnson et al. 2013; Sabean 2007a, 2007b), such patterns displaced structures of inheritance and succession that had led them to talk of patrilines and agnatic lineages, those earlier formations had themselves emerged with new claims for family definitions. The "passage from the 
Middle Ages to the early modern period," Sabean and Teuscher (2007: 14-15) write, witnessed "more well-established family strategies," as in the "patrilineal and similarly exclusive conceptions of kin organization [that] acquired an almost constitutional status." What conceptions of individuals were evolving here? Is this identity already in the making? In the language I have been using, do kin alliances as such come to enact a form of external relations between units increasingly imagined as discrete-whether between lineages, families, or conjugal households?

This is worth briefly enlarging upon. Various developments seem to have coalesced in the seventeenth century. These included a shift from what writers refer to as kin connections based on extensive collateral relations, with women as well as men having interests in family property, to the delineation of those lineages emphasizing descent and property accumulation through men. While these changes clearly affected those with property, they were not confined to such considerations. Davis (1978) describes family strategies in sixteenth- and seventeenth-century France that came from a wide social spectrum and involved a consciousness of family history and family futures, meaning the conjugally based household. As significantly for our interests, Davis (1986) observes that, like families, individuals were acquiring a distinct sense of their life histories. But for those of much or little means, the 'individuality' of people and families might sharpen certain identities at the expense of others. "Women," Duhamelle (2007: 133) states, "were gradually excluded from participating in the circulation of wealth between the lineages as their shares in family goods were progressively diminished," culminating in a decision in 1653 to abolish women's inheritance claims in favor of "a new self-representation [i.e., the family] that enhanced male descent." Aspects of this account of German nobility (the Rhenish imperial knighthood) could as well have been written of ordinary folk in England. In 1670, the English Parliament intervened in the administration of probate (settling the inheritance of a deceased's estate), with the effect of undermining ordinary women's entitlement to personal property. Diverse writings on political theory of the time, Erickson (1993: 230) adds, made an "overt identification of 'the individual' [person] with the male individual."

Touching on ideas about relatedness, a momentary turn to procreative idioms of blood, away from those of flesh, enabled 'lines' of blood to be identified. ${ }^{20}$ Here one might wonder at the role of reproductive material in rendering external relations distinct and concrete. A naturalist connotation of corporeal entities as belonging to a physical world implied their being identified, and thus fixed, in relation to one another, and this went for procreative elements as well. Thus, it came to be assumed that the contributions and reproductive organs of the sexes had distinct properties with respect to each other. Drawing on materials from Italy, one historian directly addresses the development of a 'naturalist theory' of bodily transmission through inheritance: “[B]lood was identified as the substance that transmitted qualities from one generation to the next" (Delille 2013: 130). It also circulated. In seventeenth-century Europe at large, "each consanguineal link could be a conduit of blood, and each alliance, 
a sharing of blood ... [So] a group of males, an agnatic line, a house ... could express the marriage of one member with another house as a mingling of blood: [such] an alliance could only be thought of ... through a language of flows, channels, conduits, coursings, and circulations" (Sabean 2013: 145). That heritage was conferred by 'nature', blood being the carrier, is arguably what was new (Delille 2013: 127, 130). ${ }^{21}$ Blood was not alone-semen and milk had similar properties. The specific interest in blood is that it "replaced the medieval notion that generation was the result of contact between flesh" (ibid.: 135). ${ }^{22}$ If external relations between (individual) familial units were visualized in terms of flowing blood, such units in turn acquired specific identities: "Families or lineages were natural beings whose social personality rested on a foundation which today we would term biological" (ibid.: 132).

What then was to gather momentum in the eighteenth century was a stress on alliances between families through marriage, alongside the (social) classconsciousness of desirable investment in same-status matches. This contributed to a fresh focus on conjugality, for "marriage-as-alliance ... expressly put the interest of the new [conjugal] unit above the interests of either of the spouses' natal families" (Perry 2004: 231). ${ }^{23}$ One may wonder in fact whether the pleasures and perils of close marriage typical of the (upper) middle-class England of the nineteenth century were not a hypertrophied outcome of the value placed on seeking 'good connections'. This was a time when marriages between cousins or brothers- and sisters-in-law were as common among doctors, lawyers, and clergymen as they were in business, not to mention the intellectual and scientific bourgeois (Kuper 2009: 135). Often the unions were explicitly between families, such as among elite Quakers prominent in banking. Crucially, marriage repeated between families merged into a sense of marriage "within the family" (ibid.: 27), an ideal arrangement of the Victorian novel, for example, being adoption "into the family [of] someone who is almost a member of the family already" (Valerie Sanders, cited in ibid.: 17).

We might detect a naturalist cosmology in the naturalization of substances. Anticipated in the period of biology before biology, so to speak, we might also detect that there is nothing innocent in the naturalization of relations either.

\section{Language Effects and Concealments}

Carsten's (2004: 107) rethinking of personhood and kinship led her to call for an appreciation of Western people's "everyday sense of relationality." The question, then, as she makes clear, is how the world ever made such an appeal to an appreciation of relations necessary. What is being emphasized and what gets overlooked? Her point is that discussions of the person that emphasize "the notion of an abstract and legally defined entity, the bounded individual with rights over property ... [has] obscured the most obvious contexts in which relationality as an aspect of personhood is expressed" (ibid.), namely, kinship. In other words, it is the relationality of kinspersons (the linguistic relationality of kin designations never being in doubt) that is obscured. Carsten refers to 
these (interpersonal) relations as intrinsic to the person. Was it descriptions and enactments of relations-including kin relations-as external to the person that obscured them?

For users and speakers of English, there is particular significance to the local expositions mentioned here. The foray into European kinship was intended to localize or parochialize the English examples. Clearly, events were happening elsewhere of which developments in England were but one version, and its spokesmen (to put it like that) but players on a wider stage. Israel's (2001: 515) reference to the Anglomania that swept Europe in the 1730s and 1740s, when Locke-along with Bacon and Newton-were "almost everywhere eulogized and lionized," is in the context of a reflection on the radical potentials of European intellectual life at large. Locke, intellectually 'safe' in his view, contributed little and late to the European Enlightenment. But ideas flow with language regardless of their credibility. The entwining of kinship ties and relations may have been an incidental division of subject matter in Locke's account. However, and peculiar to linguistic idioms in English, the entwining was concretized in the idiomatic adoption of relations as a substantive for kinsfolk: relations, relatives, meaning kin. Its wide usage dates from the seventeenth century. One wonders what English users anywhere would have made of relations as an abstract object of knowledge when so much weight seems to have been put on their externalizing effects. And for non-English speakers, the kin usage might have seemed puzzling.

Recall the language of symbiosis and those findings of zoological science that "animals [among other organisms] are composites of many species living, developing, and evolving together," presented as a matter of "inter-active relationships among species" (Gilbert et al. 2012: 326). In English, this last phrase is likely to evoke external relations. In the seventeenth century, which is when ideas about kinship were being reconfigured by the abstract term 'relation' for kinsfolk, it was arguably becoming possible to conceive of an individual person plus his or her relations or of the (conjugal) family plus its relations. Here would have been an enactment of external relations indeed-both in the way the individual entity is at once separated from such relations (i.e., [other] kinsfolk) and related to them and in the substantive 'relation' itself as an object of reflection.

Narrativizing the concepts of 'identity' and 'relation' may have thickened an appreciation of the naturalist insistence on external relations 'between' selfcontained terms. Self-containment, held in place when one distinct thing is defined by its relation to another distinct thing, gives us entities with properties but without internal relations. Philosophers debate the extent to which all relations might be internal, that is, whether any relation can leave unaffected its terms or bearers (Johansson 2014). Yet common conceptions were and are otherwise. In asking how this form of conceptualizing external relations becomes habitual, overlooking any perception of intrinsic kin ties, might we imagine that certain possibilities for reflection on new apprehensions of knowledge were long ago hidden within the naturalist concept of identity? Relations of an external kind were its correlate. That external relations (which kept nature 
and culture distinct) could often be reformulated as internal ones (each being implicated in the other) was the kind of uncovering of the 'obvious' that could become a fertile source of critical debate. ${ }^{24}$ When describing relations in the abstract, Locke himself anticipated the move in talking of concealment. Seemingly absolute terms contain relations, Locke ([1690] 1975: chap. 25:3, 320) argued, for there are "relative terms" that "under the form and appearance of signifying something absolute in the subject, do conceal a tacit, though less observable, relation," an example being the word 'stores' (as a ship lays in stores) in its having a relation to future use.

When thought of as external, relations were to give endless and highly productive trouble to an anthropology concerned with non-Euro-American forms of kinship and aspects of Euro-American forms too. Sahlins's (2013) recent synthesis may be read as uncovering the creativity of internal relations. His formulation of "mutuality of being" as implying "people who are intrinsic to one another's existence" (ibid.: 2) perhaps holds a message for the symbioticists. Whatever new vocabulary those who look to symbiogenesis may find for what English speakers currently cast as relations, internal or external, it might be helpful to be reminded of this concept's early modern molding. It is not nature versus culture, the body-mind split, the separation of the substantial being from consciousness of the self that is only of interest. The silent absence of kinship from learned discussion about the identity of either human beings or persons arguably has had consequences for biology and anthropology alike.

\section{Acknowledgments}

My warm thanks to Casper Bruun Jensen and Atsuro Morita for the opportunity to revisit nature-culture and for the particular stamp they have put on the enterprise. I am grateful to Louise Braddock, Natalie Zemon Davies, Jeanette Edwards, and Aparecida Vilaça for conversations on many aspects of these issues and, most enduringly, to Donna Haraway.

Marilyn Strathern had the good fortune to receive initial-and indelibletraining in Papua New Guinea, which led to work among other things on kinship and gender relations. In the United Kingdom, she subsequently became involved with anthropological approaches to the new reproductive technologies, intellectual property, audit cultures, and interdisciplinarity. Now retired from the Cambridge Department of Social Anthropology, she is (honorary) Life President of the Association of Social Anthropologists of the UK and Commonwealth (ASA). Strathern is currently working on issues in the conceptualization of relations, some of which are sketched out in her book Kinship, Law and the Unexpected: Relatives Are Always a Surprise (2005). 


\section{Notes}

1. I do not wish to imply familiarity with the journal; the piece was sent to me by Donna Haraway, who has long been concerned with the inherent relationality of the living world. The present article is a tangential response to a question of hers, namely, whether contemporary realizations about species symbiosis might be equal in their import to the historical moment at which Euro-American ideas about generation became ideas about production and reproduction. If one transformation happened, could another?

2. For instance, by Bowker (2010) and in actor-network theory, insofar as it "dispenses with any a priori delimitation of what can count as a relation" (Jensen and Winthereik 2013: 29). A simple superfluity of interactions in communication networks does the job too. Jensen and Winthereik also comment on Deleuze's view that "the individual, so dear to liberal philosophy and politics, is washing away in a sea of data" (ibid.: 160).

3. Viveiros de Castro (2004) himself goes on to make an argument about internal and external relations in order to engage a debate with representational thinking and its 'relativism', which is to one side of my intentions here. In quite different contexts, the concepts of internal and external relations may be used recursively, as, for example, when they correspond to or evoke a notion of the inside and outside of things. This is done by Morita (2014) in an elucidation of Mumford's machine that, in working, becomes a part of the connections surrounding it, embodying the connections in the design of its parts. Jensen's (2012: 49) distinction is close to that pursued here: "If relations are extrinsic it means that they connect terms, persons or whatever, that remain unchanged regardless of the connection. If they are intrinsic it means that relations come first, shaping the terms that are purportedly connected."

4. As discussed by Jensen and Winthereik (2015), following Latour.

5. Reflecting semi-autobiographically on how to make an anthropology of the 'Moderns' possible, Latour (2013a) refers to frenzied users of nature-culture schema as 'Naturalists'. The way ahead, as he sees it, is in discarding the smokescreen thrown up by notions of nature and an exterior material world. In practice, he adds, the frenzied users of this schema do something else entirely. However, Descola (2013) is more interested in 'naturalism' as itself a permutation of other possibilities, so it is appropriate for his argument to keep certain established characterizations of nature-culture intact.

6. Such marriages were confined very largely to that century. In Britain, cousin marriages were legally permissible, but morally often the source of soul-searching.

7. Specifically, and notoriously peculiar to England, the permissibility of a man's marriage with a deceased wife's sister (see Kuper 2009).

8. The idea that each species acts according to its own nature has a long history in European thought. However, by contrast with the 'chain of being' that "from the early seventeenth century onward ... gradually lost its analogical dimension and soon was employed only as a familiar metaphor in the service of naturalist ontology" (Descola 2013: 205), nature in the sense of a quality intrinsic to something seems to have been reinforced by the new concept of identity.

9. What to naturalists is uncertainty, or inadequate knowledge, can be held at bay in an analogic cosmology by rearranging the elements in question (e.g., through omen and revelation). Naturalists cannot 'control' the natural world in this way. They can uncover it, exploit it, change it, and in that sense master it with human inventions. But they cannot reorder it, insofar as each epistemic reordering is attributable to 
filling a gap in human knowledge and thus appears as a human intervention (reordering understood as an act of human interpretation).

10. Not just "the modern western conception of the human" (Vaisman 2013: 106), but a specific concept of the 'individual' appears at the same time as the separation of nature and culture. In bringing together these two confluences, Vilaça (2013: 364) adds that it is hardly "a novel correlation" (citing Dumont).

11. Witness the definitive volume of Ingold and Palsson (2013), which takes up what has long been a dominant theme in Ingold's oeuvre, the mutual interpenetration of biological and social understandings in a larger understanding of life.

12. 'New' in the sense of reconceived or reformulated, not originary.

13. Although there was a precursor in French and late Latin, as far as English is concerned, the 1979 Oxford English Dictionary (p. 1368) remarks of this period: "Various suggestions have been offered as to the formation. Need was evidently felt of a noun ... to express the notion of 'sameness', side by side with those of 'likeness' and 'oneness.'” 'Individual' also came into its own at this time. Originally a term for an indivisible entity, it became used in the seventeenth century for separate entities and (as an adjective) for some thing distinguished from others by attributes of its own, or (as a noun) for an object determined by properties peculiar to itself, as well as for a single member of a natural class or group.

14. I talk of Locke in part for the popularity his writing came to acquire, in part because there are interesting pointers to kinship usage in his Essay Concerning Human Understanding ([1690] 1975) - a (re)source for discussion, with no imputation as to any originating role it may have played.

15. As in the case of one of Locke's pupils, Shaftesbury, ruminating on the circumstances under which "I [may] indeed be said to be lost, or have lost My Self" (Porter 2000: 166).

16. Substance as a mass of matter has its own type of identity. Here Locke is talking of the identity of an individual organism that has a typical and distinct form, and an individual life, or what we may gloss in the case of man as referring to "human individuals" (Balibar 2013: 57). Attending to its textual location and context in arguments of the time, we may add that Balibar credits Locke with inventing the concept of consciousness.

17. "This also shows wherein the identity of the same man [as the human individual organism] consists; viz. in nothing but a participation of the same continued life, by constantly fleeting particles of matter, in succession vitally united to the same organized body" (Locke [1690] 1975: chap. 27:6, 332). Where modern readers might look forward to a nature-culture dichotomy, over Locke's shoulder were contemporary debates on the resurrection. The being accountable for his or her actions could not be the bodily enfolded and corruptible 'man' but the moral 'person' or self with its enduring identity (Sandford 2013: xxx-xxxi).

18. No mention is made of kinship although the chapter on identity and diversity is sandwiched between extensive discussions on different kinds of relations. It is the place of kin relations in Locke's account that concerns me. This is separate from the question as to whether his notion of personal identity can be parsed as a relational one (see Fausto 2012: 36, following Balibar 2013).

19. When Locke brings these concepts together, it is seemingly for purposes other than an inquiry into identity. In the introductory section on relation, a person (Caius) is taken as a "positive being" who can be described either through attributes, such as his being a man or white, or through a relative term, such as "husband," which links him to some other person, or the comparative "whiter," which links him to some other thing (Locke [1690] 1975: chap. 25:1, 319). Thought is led beyond the 
initial subject, says Locke, and in this sense any idea may be the foundation of a relation. This is an instance of (affinal) kinship being used to exemplify a logical relation-that of comparison. Here the fact that the example is of a person does bring kinship to mind, if only one among other possibilities: Caius is later imagined as compared to several persons, someone "being capable of as many relations as there can be occasions of comparing him to other things" (ibid.: chap. 25:7, 322).

20. I am very grateful to Jeanette Edwards for pointing me to Johnson et al.'s (2013) collection and for her specific comments (Edwards 2014). Carsten's (2013) work on blood is highly germane. See also both Weston and Bildhauer in Carsten (ibid.).

21. Blood flowed between parents and children and, in a restricted sense, specifically between father and child. Thus, sons might be conceived as "part of the bodies of fathers who pass on their glory to their sons," as opposed to an idea of nobility being "in the human soul” (Delille 2013: 127). In some formulations, maternal blood was externalized by its circulating properties. The time span that Delille discusses ranges from the latter half of the fifteenth to the seventeenth century, by which time these ideas were consolidated. He also describes opposition to these theories from both church and state.

22. Flesh, like blood, had it own genealogy, one that we cannot pursue here. When it was 'flesh' that depicted the (carnal) union of spouses and their procreative intent, some of the virtues of 'blood' were instead bound up with the blood of sacrifice and its analogy with baptismal water in Christian thought.

23. Following the arguments of Trumbauch, Perry (2004) is comparing eighteenthcentury aristocratic and middle-class marriages in England.

24. This is exactly the move made by Wagner (1977) in the famous opening to "Analogic Kinship." Against prevailing assumptions about the innateness of kin differentiation, he asks us to imagine that "all human relationships [including all kin relations] are analogous to one another" (ibid.: 623).

\section{References}

Balibar, Étienne. 2013. Identity and Difference: John Locke and the Invention of Consciousness. Ed. Stella Sandford; trans. Warren Montag. London: Verso. First published in 1998 as Identité et différence: L'invention de la conscience.

Bowker, Geoffrey C. 2010. "A Plea for Pleats.” In Deleuzian Intersections: Science, Technology, Anthropology, ed. Casper Bruun Jensen and Kjetil Rödje, 123-138. New York: Berghahn Books.

Carsten, Janet. 2004. After Kinship. Cambridge: Cambridge University Press.

Carsten, Janet, ed. 2013. Blood Will Out: Essays on Liquid Transfers and Flows. Malden, MA: Wiley-Blackwell.

Davidoff, Leonore. 2012. Thicker Than Water: Siblings and Their Relations, 1780-1920. Oxford: Oxford University Press.

Davis, Natalie Z. 1978. "Ghosts, Kin, and Progeny: Some Features of Family Life in Early Modern France.” In The Family, ed. Alice S. Rossi, Jerome Kagan, and Tamara K. Hareven, 87-114. New York: W. W. Norton.

Davis, Natalie Z. 1986. "Boundaries and the Sense of Self in Sixteenth-Century France." In Reconstructing Individualism: Autonomy, Individuality, and the Self in Western Thought, ed. Thomas C. Heller, Morton Sosna, and David E. Wellbery, 53-63. Stanford, CA: Stanford University Press. 
Delille, Gérard. 2013. "The Shed Blood of Christ: From Blood as Metaphor to Blood as Bearer of Identity.” In Johnson et al. 2013, 125-143.

Descola, Philippe. 2013. Beyond Nature and Culture. Trans. Janet Lloyd. Chicago: University of Chicago Press. Originally published in 2005 as Par-delà nature et culture.

Duhamelle, Christophe. 2007. "The Making of Stability: Kinship, Church, and Power among the Rhenish Imperial Knighthood, Seventeenth and Eighteenth Centuries." In Sabean et al. 2007, 125-144.

Edwards, Jeanette. 2014. "Tugging on a Thread (of Thought): A Comment on Marilyn Strathern's 'Anthropological Reasoning.'” HAU: Journal of Ethnographic Theory 4 (3): 39-44.

Erickson, Amy L. 1993. Women and Property in Early Modern England. London: Routledge.

Fausto, Carlos. 2012. "Too Many Owners: Mastery and Ownership in Amazonia." In Animism in Rainforest and Tundra: Personhood, Animals, Plants and Things in Contemporary Amazonia and Siberia, ed. Marc Brightman, Vanessa E. Grotti, and Olga Ulturgasheva, 29-48. New York: Berghahn Books.

Gilbert, Scott F., Jan Sapp, and Alfred I. Tauber. 2012. "A Symbiotic View of Life: We Have Never Been Individuals." Quarterly Review of Biology 87 (4): 325-341.

Ingold, Tim, and Gisli Palsson, eds. 2013. Biosocial Becomings: Integrating Social and Biological Anthropology. Cambridge: Cambridge University Press.

Israel, Jonathan I. 2001. Radical Enlightenment: Philosophy and the Making of Modernity, 1650-1750. Oxford: Oxford University Press.

Jensen, Casper Bruun. 2012. "Proposing the Motion: The Task of Anthropology Is to Invent Relations." Critique of Anthropology 32 (1): 47-53.

Jensen, Casper Bruun, and Brit Ross Winthereik. 2013. Monitoring Movements in Development Aid: Recursive Partnerships and Infrastructures. Cambridge, MA: MIT Press.

Jensen, Casper Bruun, and Brit Ross Winthereik. 2015. "Test Sites: Attachments and Detachments in Community-Based Ecotourism." In Detachment: Essays on the Limits of Relational Thinking, ed. Matei Candea, Joanna Cook, Catherine Trundle, and Thomas Yarrow, 197-218. Manchester: Manchester University Press.

Johansson, Ingvar. 2014. "All Relations Are Internal: The New Version.” In Mind, Values, and Metaphysics, ed. Anne Reboul, 225-240. New York: Springer.

Johnson, Christopher H., Bernhard Jussen, David W. Sabean, and Simon Teuscher, eds. 2013. Blood and Kinship: Matter for Metaphor from Ancient Rome to the Present. New York: Berghahn Books.

Kuper, Adam. 2009. Incest and Influence: The Private Life of Bourgeois England. Cambridge, MA: Harvard University Press.

Latour, Bruno. 2013a. "Biography of an Inquiry: On a Book about Modes of Existence." Social Studies of Science 43 (2): 287-301.

Latour, Bruno. 2013b. An Inquiry into Modes of Existence: An Anthropology of the Moderns. Trans. Catherine Porter. Cambridge, MA: Harvard University Press.

Law, John. 1994. Organizing Modernity. Oxford: Blackwell.

Locke, John. (1690) 1975. An Essay Concerning Human Understanding. Ed. Peter H. Nidditch. Oxford: Clarendon Press.

Morita, Atsuro. 2014. "The Ethnographic Machine: Experimenting with Context and Comparison in Strathernian Ethnography." Science, Technology \& Human Values 39 (2): 214-235.

Perry, Ruth. 2004. Novel Relations: The Transformation of Kinship in English Literature and Culture, 1748-1818. Cambridge: Cambridge University Press.

Porter, Roy. 2000. Enlightenment: Britain and the Creation of the Modern World. London: Allen Lane. 
Sabean, David W. 2007a. "Transition 1: From Medieval to Early Modern Kinship Patterns. Outline and Summaries." In Sabean et al. 2007, 51-56.

Sabean, David W. 2007b. "Transition 2: From Early Modern to Nineteenth-Century Kinship Patterns. Outline and Summaries." In Sabean et al. 2007, 187-193.

Sabean, David W. 2013. "Descent and Alliance: Cultural Meanings of Blood in the Baroque." In Johnson et al. 2013, 144-174.

Sabean, David W., and Simon Teuscher. 2007. "Kinship in Europe: A New Approach to Long-Term Development.” In Sabean et al. 2007, 1-32.

Sabean, David W., Simon Teuscher, and Jon Mathieu, eds. 2007. Kinship in Europe: Approaches to Long-Term Developments (1300-1900). New York: Berghahn Books.

Sahlins, Marshall. 2013. What Kinship Is-and Is Not. Chicago: University of Chicago Press.

Sandford, Stella. 2013. "Introduction. The Incomplete Locke: Balibar, Locke and the Philosophy of the Subject.” In Balibar 2013, xi-xlvi.

Taylor, Charles. 1989. Sources of the Self: The Making of the Modern Identity. Cambridge: Cambridge University Press.

Vaisman, Noa. 2013. "Shedding Our Selves: Perspectivism, the Bounded Subject and the Nature-Culture Divide.” In Ingold and Palsson 2013, 106-122.

Vilaça, Aparecida. 2013. "Reconfiguring Humanity in Amazonia: Christianity and Change." In A Companion to the Anthropology of Religion, ed. Janice Boddy and Michael Lambek, 363-386. Malden, MA: Wiley-Blackwell.

Viveiros de Castro, Eduardo. 2004. "Exchanging Perspectives: The Transformation of Objects into Subjects in Amerindian Ontologies.” Common Knowledge 10 (3): 463-484.

Wagner, Roy. 1977. “Analogic Kinship: A Daribi Example.” American Ethnologist 4 (4): 623-642. 